\title{
Desafios enfrentados pelas pessoas com doença falciforme nas situações de crise: Entraves nos serviços de emergência
}

\author{
Challenges faced by people with sickle cell disease in crisis situations: Barriers to emergency \\ Desafíos que enfrentan las personas con anemia de células falciformes en situaciones de crisis:
}

Barreras a los servicios de emergencia

Recebido: 14/04/2021 | Revisado: 25/04/2021 | Aceito: 28/04/2021 | Publicado: 13/05/2021

\author{
Débora Silveira de Lima \\ ORCID: https://orcid.org/0000-0002-4841-2333 \\ Universidade Estadual do Ceará, Brasil \\ E-mail: debora.s1001@gmail.com \\ Sarah Vieira Figueiredo \\ ORCID: https://orcid.org/0000-0003-1014-086X \\ Universidade Estadual do Ceará, Brasil \\ E-mail: sarahvfigueiredo@gmail.com \\ Ana Caroline Araujo da Silva \\ ORCID: https://orcid.org/0000-0001-7864-8761 \\ Universidade Estadual do Ceará, Brasil \\ E-mail: anacaroline222324@gmail.com \\ Maria Eunice Nogueira Galeno Rodrigues \\ ORCID: https://orcid.org/0000-0002-3245-3712 \\ Universidade Estadual do Ceará, Brasil \\ E-mail: eunicegaleno@hotmail.com \\ Samila Sousa Vasconcelos \\ ORCID: https://orcid.org/0000-0002-1509-1887 \\ Centro Universitário Inta, Brasil \\ E-mail: samilasousa@hotmail.com \\ Cláudia Patrícia da Silva Ribeiro Menezes \\ ORCID: https://orcid.org/0000-0002-0559-9302 \\ Universidade Estadual do Ceará, Brasil \\ E-mail:claudia_ribeiro6@ hotmail.com \\ Lívia Lopes Custodio \\ ORCID: https://orcid.org/0000-0001-9610-7379 \\ Universidade Estadual do Ceará, Brasil \\ E-mail: liviacustodio@yahoo.com.br \\ Leticia Alexandre Lima \\ ORCID: https://orcid.org/0000-0003-2566-0315 \\ Universidade Estadual do Ceará, Brasil \\ E-mail: leticia_lima1@hotmail.com \\ Débora Pena Batista e Silva \\ ORCID: https://orcid.org/0000-0003-0633-5242 \\ Universidade Estadual do Ceará, Brasil \\ E-mail: pbs.debora@gmail.com \\ Débora Cristina Couto Oliveira Costa \\ ORCID: https://orcid.org/0000-0002-9402-0613 \\ Universidade Estadual do Ceará, Brasil \\ E-mail: deboraccoc@gmail.com \\ Macedônia Pinto dos Santos \\ ORCID: https://orcid.org/0000-0003-1582-2720 \\ Universidade Estadual do Ceará, Brasil \\ E-mail: macedonia.pinto@gmail.com \\ Ilvana Lima Verde Gomes \\ ORCID: https://orcid.org/0000-0002-1861-5121 \\ Universidade Estadual do Ceará, Brasil \\ E-mail: ilverde@gmail.com
}

\section{Resumo}

Objetivo: Identificar os desafios enfrentados por pessoas com doença falciforme na Rede de Atenção à Saúde. Método: estudo descritivo com abordagem qualitativa, realizada totalmente via aplicativo de mensagens instantâneas de texto e de áudio com 40 pessoas, por meio de uma entrevista estruturada questionando quanto à satisfação dos participantes em relação à assistência que recebiam durante as crises de dor. Resultado: A média de idade foi de 18,7 com prevalência 
da cor parda. Constatou-se que $85 \%$ do público dirige-se às instituições públicas durante as crises de dor. Percebeu-se, também, que poucos profissionais compreendem a doença falciforme e, por isso, prestam uma assistência de baixa qualidade. Conclusão: percebeu-se que o maior desafio enfrentado pelos participantes foi a insatisfação quanto ao atual modelo assistencial principalmente nas instituições públicas faz-se necessário um investimento na capacitação dos profissionais de saúde nos diferentes níveis de assistência, para que o cuidado seja integral e eficaz.

Palavras-chave: Anemia falciforme; Doença crônica; Assistência à saúde.

\begin{abstract}
Objective: to identify the challenges faced by people with sickle cell disease in the Health Care Network. Method: a descriptive study with a qualitative approach, carried out entirely via text and audio instant messaging with 40 people, through a structured interview asking how much participants' satisfaction with the assistance they received during pain crises. Result: The average age was 18.7 with a prevalence of brown color. It was found that $85 \%$ of the public goes to public institutions during pain crises. It was also noticed that few professionals understand sickle cell disease and, therefore, provide low quality care. Conclusion: given the dissatisfaction with the current care model, especially in public institutions, it is necessary to invest in the training of health professionals at different levels of care, so that care is comprehensive and effective.
\end{abstract}

Keywords: Sickle cell anemia; Chronic disease; Health assistance.

\title{
Resumen
}

Objetivo: Identificar los desafíos que enfrentan las personas con anemia falciforme en la Red de Salud. Método: estudio descriptivo con enfoque cualitativo, realizado íntegramente a través de mensajería instantánea de texto y audio con 40 personas, mediante una entrevista estructurada preguntando cuánto la satisfacción de los participantes con la asistencia que recibieron durante las crisis de dolor. Resultado: La edad promedio fue de 18,7 años con predominio de color marrón. Se encontró que el $85 \%$ del público acude a las instituciones públicas durante las crisis de dolor. También se observó que pocos profesionales comprenden la enfermedad de células falciformes y, por tanto, brindan una atención de baja calidad. Conclusión: dada la insatisfacción con el modelo de atención actual, especialmente en las instituciones públicas, es necesario invertir en la formación de los profesionales de la salud en los diferentes niveles de atención, para que la atención sea integral y eficaz.

Palabras clave: Anemia de células falciformes; Enfermedad crónica; Asistencia sanitaria.

\section{Introdução}

A Doença Falciforme (DF) é considerada pela Organização Mundial de Saúde (OMS), um grave problema de Saúde Pública que apresenta grande impacto na população afetada. A DF é o termo utilizado para englobar um grupo de anemias hemolíticas hereditárias determinadas pelo gene Hemoglobina $\mathrm{S}(\mathrm{HbS})$. Ademais, a DF é a doença hereditária mais prevalente no mundo e afeta principalmente pessoas com formação étnica africana (OPAS, 2017; Gomes et al., 2019).

De acordo com os dados da OMS, no Brasil nascem cerca de 2.500 crianças/ano com doença falciforme, entretanto, conforme os dados do Programa Nacional de Triagem Neonatal (PNTN) mostram uma incidência superior, de 3.500/ano entre os nascidos vivos (OPAS, 2017).

Neste contexto, na DF há uma diminuição na concentração de hemoglobina no sangue abaixo do normal para idade, sexo e área geográfica ocasionando hemólise intra e extravascular de eritrócitos irreversivelmente. Provoca sinais e sintomas que incapacitam e dificultam a vida laboral de pessoas como as crises álgicas, úlceras de membros inferiores, Síndrome Torácica Aguda (STA), sequestro esplênico, priapismo, necrose asséptica do fêmur, Acidente Vascular Encefálico (AVE), retinopatia, Insuficiência Renal Crônica (IRC) e outros (Manga; Debaun \& Kassim, 2016).

Nesta perspectiva, os cuidados a pessoa com doença falciforme devem ser iniciados já nos primeiros dias de vida. Para Araújo et al. (2020), as crianças portadoras de DF, bem como os adultos, precisam de cuidados especiais devido aos seus sintomas que podem evoluir para graves crises dolorosas que impactam na vida dos mesmos. Portanto, se torna indispensável uma assistência multiprofissional e multidisciplinar a esse público, que se faça presente em todas as áreas a fim de manter ou garantir um cuidado integral aos usuários do sistema público de saúde (Alvarez et al., 2019).

Neste âmbito, a Política Nacional de Atenção Integral às Pessoas com Doença Falciforme garante o direito de acolhimento no fomento das Redes de Atenção à Saúde (RAS), composta por ações e serviços de saúde articulados em diferentes 
níveis de complexidade, com a finalidade garantir a integralidade da assistência à saúde e a formação de relações horizontais entre os pontos de atenção, tendo a Atenção Básica como centro de comunicação (Brasil, 2014).

Por outro lado, estudos apontam que existe uma fragilidade e insatisfação no cuidado ofertado pela Atenção Primária às pessoas com a doença falciforme. Tal problema está evidenciado, principalmente, pela falta de conhecimento dos profissionais de saúde sobre essa doença hematológica (Almeida; Santos \& Silva, 2018).

Assim sendo, a presente pesquisa poderá sensibilizar os profissionais de saúde da importância do conhecimento para produzirem um cuidado integral, formando vínculos e estimulando a corresponsabilização, a fim de organizar um cuidado baseado nas necessidades singulares de cada indivíduo.

Desse modo, visando uma compreensão maior, nos demais serviços de saúde disponibilizados pelo SUS, a presente pesquisa objetivou investigar os desafios enfrentados por pessoas com doença falciforme na Rede de Atenção à Saúde.

\section{Metodologia}

O estudo adotou uma perspectiva descritiva com abordagem qualitativa. A população do estudo foi composta por pessoas com DF ou responsáveis por pacientes com DF. Já a amostra do estudo foi composta pelos participantes de um grupo de uma rede social chamado Família Acefal! e por pacientes que já fizeram parte de pesquisas do grupo de pesquisa Doenças Crônicas em Crianças e Adolescentes, Família, Saúde Coletiva e Enfermagem (DOCAFS) Universidade Estadual do Ceará.

Foram considerados os critérios de inclusão: Ter doença falciforme, ser maior de 18 anos ou ser responsável por criança e adolescente falcêmico e ser acompanhado no estado do Ceará. Já o critério de exclusão foi ter déficit cognitivo que impeça de responder as perguntas.

Este estudo seguiu a Resolução 466/12 do Conselho Nacional de Saúde e foi submetido ao Comitê de Ética em Pesquisa da Universidade Estadual do Ceará, sendo aprovado sob parecer número 3.574.112. Quando havia confirmação do participante com interesse na pesquisa, o Termo de Consentimento Livre e Esclarecido (TCLE) era enviado ao participante. O aceite da pesquisa foi gravado após a leitura do TCLE e entendimento do participante sobre a pesquisa (Brasil, 2012). Para manter o anonimato dos entrevistados e garantir o cumprimento dos preceitos éticos e legais, eles foram identificados por códigos (N1, $\mathrm{N} 2, \mathrm{~N} 3 \ldots \mathrm{N} 40$ ) sem guardar relação com a ordem das entrevistas.

As entrevistas foram realizadas por um aplicativo de mensagens de texto e de áudio. A coleta de dados ocorreu entre os meses de setembro de 2019 e janeiro de 2020, após inicialmente o pesquisador lançar um convite aos participantes do grupo de uma rede social, no qual faz parte, chamado Família Acefal!!!!. Tal grupo possui um total de 49 participantes, dentre eles estão quatro profissionais, incluindo o pesquisador.

Visto que nem todos quiseram participar da pesquisa, foi necessário entrar em contato, também, pelo aplicativo de mensagens, com uma lista de 82 pessoas que já haviam participado de pesquisas relacionadas a DF realizadas pelo grupo de pesquisa Doenças Crônicas em Crianças e Adolescentes, Família, Saúde Coletiva e Enfermagem (DOCAFS) Universidade Estadual do Ceará (UECE) no qual a pesquisadora faz parte.

A estratégia utilizada foi a amostragem por conveniência. Primeiramente, 14 pessoas se prontificaram a participar e logo após, entrou-se em contato com mais 82 pessoas da lista e destas 27 quiseram participar. No entanto, um dos participantes foi excluído da pesquisa por não atender aos critérios de inclusão, totalizando ao final 40 entrevistados.

Para coletar os dados da pesquisa foi utilizada a entrevista estruturada no qual as perguntas eram feitas por mensagem de texto ou áudio dependendo da necessidade de cada pessoa. Quando o participante era menor de idade as perguntas eram feitas ao seu responsável. Na primeira parte da entrevista, foram feitos questionamentos para traçar o perfil dos entrevistados. Na segunda parte, foi questionado sobre o serviço de saúde em que realizam o acompanhamento e a satisfação com o cuidado prestado nos locais. 
A estratégia de análise foi de acordo com as técnicas de análise de conteúdo temático de Bardin (2011). Então, foi realizada inicialmente uma leitura das falas as agrupando de acordo com suas semelhanças e divergências quanto aos temas em comum. A média de palavras ditas de cada participante foi igual a 21, revelando que os participantes davam respostas eram concisas e objetivas ao que era questionado.

\section{Resultados}

A partir da análise das entrevistas dos participantes, dividiu-se a apresentação dos resultados em: Caracterização dos participantes e duas categorias, cujos conteúdos manifestos apresentavam maior correlação. As categorias foram: Buscando o cuidado na crise álgica e $\mathrm{O}$ (des)cuidado profissional.

\subsection{Caracterização dos participantes}

Na população composta por 40 pessoas destacou-se o perfil destes quanto ao nível de escolaridade, procedência, tipo de doença, buscando discutir tais informações, relacionando-as à realidade vivenciada pela população em questão, dentre outros.

Dentre os pesquisados, 72,5\% apresentava o tipo Anemia Falciforme (SS), sendo 28 do sexo feminino e 12 masculino; a média de idade foi de 18,7 anos. Metade da população entrevistada era composta por crianças e adolescentes, portanto, as informações foram fornecidas por seus responsáveis. Quanto à cor, $80 \%$ da população declarou-se parda.

Todos os participantes são residentes no Ceará, sendo $65 \%$ da zona urbana e $35 \%$ da zona rural de diferentes municípios do interior do Estado. Referente ao acompanhamento de crianças e adolescentes, 14 fazem acompanhamento no Hospital Infantil Albert Sabin (HIAS), sendo metade delas advindas do interior do estado. Dos adultos, 12 realizam acompanhamento no Hemocentro de Fortaleza (HEMOCE), porém, quatro deles não residem na capital. Os demais participantes, no geral, encaminham-se aos Hemocentros mais próximos de suas residências como: Crato, Iguatu, Sobral e Quixadá.

Durante as crises de dor, $90 \%$ dos 32 participantes que procuram os serviços de saúde, se dirigem às instituições públicas e dentre elas estão: Hospitais (51,7\%), Unidades de Pronto Atendimentos (UPAs) (37,9\%), Centros de Saúde da Família (10,4\%). O restante deles dá preferência às instituições particulares, que por sua vez contou apenas com unidades de níveis terciários.

\subsection{Categoria 1: buscando o cuidado na crise álgica}

Com relação ao cuidado prestado, 34\% dos entrevistados que buscam os serviços de saúde no momento da crise álgica, relataram satisfação com o atendimento recebido, como é possível avaliar nos relatos abaixo:

Sim, o atendimento é rápido e ela é bem tratada (N8)

Sim, eles têm um conhecimento da doença e sabem como agir (N18)

Em $12 \%$ dos entrevistados que procuram o atendimento no momento da crise foi percebido que embora se sentissem satisfeitos com o atendimento, enfatizaram ressalvas:

Sim, o atendimento é bom, mas não recebo nenhuma informação ou orientação (N9).

Sim, mas algumas pessoas não têm conhecimento sobre a minha doença e acham que estou fingindo a dor (N16).

Por outro lado, o restante dos participantes julgou não receber um bom atendimento durantes as crises de dor, emergindo as seguintes falas:

Não, eu preciso dar instruções pro pessoal que me atende (N21) 
Não, tem muita falta de informação no atendimento que recebo e as vezes preciso explicar o que é DF (N12)

\subsection{Categoria 2: o (des) cuidado profissional}

Por meio dos relatos dos participantes, percebeu-se que muitos falaram acerca do baixo conhecimento das equipes dos serviços de urgência e emergência sobre a doença falciforme, no sentido de implementar uma terapêutica adequada diante das situações de crise dolorosas:

Os profissionais não têm conhecimento sobre doença falciforme e não sabem o que fazer (N1).

Os profissionais não conhecem a doença e são totalmente despreparados, eles tratam como uma infecção (N6).

Não, eles me tratam super mal, não conhecem a doença e às vezes dizem que tenho outros problemas, como hepatite, e me dão medicação errada (N25).

Como citado nos relatos acima, especialmente pelos participantes 6 e 25 , essa falta de conhecimento por parte dos profissionais ainda pode dificultar no próprio enfrentamento da doença pelos pacientes, já que eles chegam a colocar em dúvida o próprio diagnóstico e tratamento, atribuindo os sintomas a infecções e outras patologias. Destaca-se ainda a forma como essa dor é percebida por alguns profissionais de saúde, que demonstram descredibilidade nos pacientes:

Não, é horrível, sempre tenho que dizer o que eles têm que fazer e às vezes dizem até que é frescura (N35).

Outro ponto a ser levado em consideração é que $20 \%$ dos participantes não buscam atendimento durante as crises de dor e, consequentemente, acabaram realizando uma boa avaliação da assistência que recebiam nos hemocentros dos quais realizavam tratamento:

Sim, ela é bem atendida por um médico especialista (no HEMOCE) (N27).

Sim, os médicos têm total conhecimento da doença e dão muita atenção a gente. A hematologista conversa sobre a doença com as mães (no HIAS) (N37).

No relato de alguns participantes, fica claro que eles condicionam a satisfação com o atendimento, com o fato dos profissionais já lhes conhecerem e ao fato de que eles mesmos precisaram explicar o que fazer. O que demonstra a necessidade de uma maior capacitação dos profissionais desses serviços sobre a DF:

Sim, agora está sendo ótimo porque as enfermeiras já me conhecem (N15).

Não, porque muitos médicos não conhecem minha doença, mas como eu sempre vou no mesmo local, alguns já me conhecem (N34).

Diante das dificuldades enfrentadas na busca por atendimento nas situações de urgência e emergência, alguns participantes declararam optar por realizar o tratamento no domicílio e não procurar auxílio, a não ser, nas situações mais graves:

Só procuro quando não consigo controlar em casa, mas não acontece com frequência (N3).

Eu sempre busco tratar ele em casa, dou bastante líquido e às vezes dipirona se tiver com febre (N5). 
Prefiro ter a minha medicação em casa, me medicar da forma que o médico passa, porque o atendimento público nas UPAs é muito defasado no que diz respeito a doença falciforme (N33).

Logo, observou-se que existem falhas nos serviços de urgência e emergência no atendimento das pessoas com DF, na medida em que, de acordo com os participantes, há uma carência de conhecimento sobre as terapêuticas adequadas nas situações de crises.

\section{Discussão}

Estima-se que aproximadamente $62 \%$ da população cearense seja da cor parda, evidenciando a estatística do estudo que revelou que $80 \%$ dos participantes declararam-se pardos, o que justifica o acometimento pela doença falciforme mais em pessoas dessa cor do que em negros (IPECE, 2012).

Rosenfeld et al. (2019) ressalta que as regiões Nordeste e Norte apresentam a maior prevalência de hemoglobinopatias, podendo ser justificada pela presença elevada de negros e pardos, principalmente no estado da Bahia. Além disso, também afirma que a incidência de talassemia beta é baixa, visto que afeta apenas 1,5\% da população brasileira. Tornando, portanto, a forma homozigota (HbSS) mais frequente. Esses resultados corroboram com o quantitativo de pessoas com DF que são acompanhadas nos serviços de referência considerando a densidade populacional e a distribuição dos genótipos, que estão de acordo com a ocorrência mundial do gene S (Sarat et al., 2019).

Além disso, observou-se que a distância pode ser um problema na adesão do tratamento, visto que alguns apresentam dificuldade no deslocamento para os hemocentros. De acordo com Gomes et al. (2019), a distância é um fator determinante que dificulta o acompanhamento ambulatorial regular. Pois, muitas vezes, a família não tem dinheiro para chegar à capital por conta própria, ficando a mercê da condução do município e quando não é disponibilizado o transporte ou a passagem, o paciente acaba faltando a consulta e prejudicando o andamento do tratamento.

Um estudo observou insatisfação nos serviços de Atenção Primária à Saúde (APS). Tal resultado mostra o baixo nível de confiança dos usuários com relação à procura das APS durante suas crises, levando-os a procurar os níveis terciários, evidenciando, assim, a baixa credibilidade dos pacientes com DF quanto ao serviço (Moraes et al., 2017). Esse fato está em consonância com relatos encontrados na presente pesquisa, em que alguns participantes relataram preferir não buscar o atendimento durante a crise.

De acordo com a população pesquisada, entende-se que os profissionais dos níveis intermediários de atenção à saúde, como as Unidades de Pronto Atendimento (UPA), desconhecem ou ignoram a enfermidade que traz a DF dentro das linhas de cuidados. Semelhante aos achados apresentados, a pesquisa realizada por Castilho, Braun e Lima (2016), cita a carência de informação por meio dos profissionais da saúde fazendo com que, consequentemente, o atendimento prestado seja de baixa qualidade, não atendendo todas as necessidades que o paciente precisa.

Dentro desse contexto, os resultados da pesquisa revelam que as pessoas dão preferência a rede terciária nos momentos de crise de dor, tendo em vista que 51,7\% buscaram as unidades hospitalares, negligenciando os outros níveis de atenção à saúde que, por sua vez, segundo os usuários, se mostraram ineficazes quanto ao cuidado.

Assim como nos achados apresentados no presente estudo, uma pesquisa realizada em 2018 por Oliveira et al. (2018), observou que algumas famílias apresentavam apoio insuficiente dos serviços de atenção primária, secundária e terciária, com exceção dos hemonúcleos, lugar onde se realiza o acompanhamento. Ademais, a fala dos usuários da rede particular do interior do estado indica falhas quanto à assistência prestada.

Os sistemas fragmentados de atenção à saúde são aqueles que se organizam de forma isolada e que, por consequência, são incapazes de horizontalizar a atenção à população. Neles, a atenção primária não se comunica com a atenção secundária que 
também não se articula com a atenção terciária, nem com os sistemas de apoio, nem com os sistemas logísticos. Diferentemente do que é proposto pela RAS que busca o fim da fragmentação do sistema de saúde e um melhor funcionamento políticoinstitucional (Lapão, 2017).

As crises dolorosas da DF são inesperadas e quando ocorrem lesionam quaisquer órgãos e/ou tecidos produzindo quadros de grande gravidade e intensidade de dor que impactam diretamente na qualidade de vida do paciente. Frente a isso, fazse necessário que se busque atendimento imediato nos serviços de atenção à saúde a fim de prevenir complicações (Custódio, 2017).

Com relação à opinião dos participantes quanto à assistência que receberam durante os momentos de crise, observouse que apesar de 55\% deles alegarem um bom atendimento, emergiu o questionamento quanto ao que estava sendo avaliado. De acordo com Esperidão e Trad (2006), as pesquisas brasileiras revelam que os usuários se satisfazem, além dos serviços de saúde, com serviços humanitários como a disponibilidade de insumos. Por isso, embora a maioria dos integrantes da pesquisa relatarem um bom atendimento, percebe-se que após feita análise, as falam mostraram-se contraditórias, visto que, os profissionais deixaram a desejar quanto a falta de orientação e de empatia.

Por outro lado, alguns indivíduos opinaram que o cuidado prestado foi ineficiente, em virtude do mau atendimento recebido durante as crises de dores. Eles, ainda, atrelaram essa conduta devido ao despreparo profissional e a desvalorização da dor. Além disso, observou-se que todos os integrantes falaram das fragilidades da rede.

De acordo com as falas evidencia-se que a falta de conhecimento dos profissionais sobre a doença leva a um atendimento de baixa qualidade. A falta de informação é uma das principais causas de uma assistência inadequada, por isso, torna-se indispensável que os profissionais de saúde e educação estejam preparados para atender esse público. Desta forma, a desinformação destaca-se como um fator de muita influência na assistência à saúde, tanto por parte de médicos quanto de outros profissionais da saúde (Monteiro, 2017).

Nesse sentido, evidencia-se que há uma escassez de orientações advindas dos serviços de saúde. Este fato reflete acerca das compreensões errôneas que a pessoa com DF e cuidadores têm a respeito da doença, visto que, as fontes de busca nem sempre são confiáveis. Desse modo, percebe-se que apesar de ser atendido, houve ausência de informações importantes sobre a doença que são de suma importância quanto à prevenção de complicações, dos cuidados na alimentação, da manutenção constante da hidratação, dentre outras questões (Figueiredo et al, 2018; Silva et al., 2013).

Em uma pesquisa de mais de uma década já se referia essa falha no conhecimento do profissional, segundo Kikuchi (2007), quando os pacientes ou seus familiares procuram os serviços de saúde, seja na atenção básica, urgência ou unidades de internação, se deparam com profissionais inseguros, pouco preparados para prestarem uma atenção qualificada à pessoa com DF; evidenciando, assim, a quebra da assistência.

Assim, devido a um mau atendimento identifica-se em algumas falas a preferência pelo cuidado domiciliar. Dessa forma, apoiar o autocuidado e prover orientações preventivas de saúde às pessoas com doença crônica diminui as barreiras entre os serviços de saúde e a população, principalmente nos países com diversos problemas sociais e escassez de orçamento e recursos humanos (Pereira et al., 2018).

Visto esse problema referente à assistência, percebe-se a necessidade de propagação do conhecimento a respeito da doença falciforme nas demais regiões do Ceará. Já que, a falta de contato dos profissionais com a doença falciforme os faz cometer erros que causam bastante impacto no cuidado à pessoa com DF.

\section{Considerações Finais}

Por meio deste estudo, foi possível compreender alguns dos desafios enfrentados pelas pessoas com DF ao buscarem atendimento nas situações de crise. $\mathrm{O}$ desconhecimento sobre a DF por parte dos profissionais aparece como a raiz do problema, 
havendo uma inversão dos papéis, em que os pacientes e seus familiares sentem-se na responsabilidade de explicarem aos profissionais sobre a DF, necessitando, em alguns casos de detalhar quais exames precisam ser pedidos e qual o tratamento adequado.

Somado à falta de conhecimento, percebe-se falhas na humanização do atendimento, em que alguns profissionais chegam a duvidar dos pacientes e até questionar o diagnóstico. Tal situação reflete alguns pontos negativos existentes na equipe de enfermagem, visto que, é ela quem normalmente realiza a avaliação inicial. Esses desafios fazem com que alguns pacientes optem por manejarem as situações de crise em domicílio, já que não sentem segurança no atendimento.

Destarte, nota-se que o presente estudo desvelou a importância da assistência de enfermagem a pacientes com doença falciforme. Assim, visto que, através das falas observou-se aspectos a serem trabalhados por parte da equipe de enfermagem no manejo adequado desses pacientes. Sendo relevante conhecer e identificar os conceitos da doença falciforme, a fim de garantir ao paciente uma técnica segura e empática durante o atendimento assistencial.

A realização desta pesquisa possibilitou um maior entendimento acerca do funcionamento e articulação da rede de atenção à saúde, voltada à assistência dos pacientes com DF. Espera-se, por meio deste estudo, uma maior sensibilização dos profissionais para produzirem a longitudinalidade do cuidado com intuito de alcançar a integralidade da assistência. Isso será possível através da formação de vínculos, confiança, empatia e corresponsabilização a fim de organizar um cuidado baseado nas necessidades singulares de cada indivíduo.

\section{Referências}

Almeida, M. M.; Santos, M. S. \& Silva, F. W. T. (2018) Assistência de enfermagem na doença falciforme na Estratégia Saúde da Família. Rev. Fund. Care Online, 10 (1), 36-45.

Alvarez, O. A. et al. (2019). Newborn screening for sickle cell disease using point-of-care testing in low-income setting. Observational Study Pediatrics, 144(4), e20184105.

Araújo, F. C. et al. (2020). Diagnóstico precoce da anemia falciforme: uma revisão da literatura. Research, Society and Development, 9(4), e.79942516.

Bardin, L. (2011). Análise de conteúdo. Edições 70.

Brasil. Resolução 466/2012. (2012). Diretrizes e normas regulamentadoras de pesquisas envolvendo seres humanos. Ministério da Saúde/Conselho Nacional de Saúde, Brasília.

Brasil. Ministério da Saúde. Secretaria de Atenção à Saúde. Departamento de Atenção Hospitalar e de Urgência (2014). Doença falciforme: enfermagem nas urgências e emergências: a arte de cuidar. Ministério da Saúde.

Castilho, L. G.; Braun, J. B. S. \& Lima, S. B. S. (2016) Atenção primária e doença falciforme: uma revisão sobre o papel do gestor. Saúde (Santa Maria), Suplemento - Artigos de revisão, 45-52.

Custódio, L. L. et al. (2017). Drawing pain for children with sickle cell anemia: the pain that hurts, really hurts. Rev Dor, 18 (40, $321-6$.

Esperidião, M. A. \& Trad, L. A. B. (2006). Avaliação de satisfação de usuários: considerações teórico-conceituais. Cad. Saúde Pública, 22 (6), 1267-1276.

Figueiredo, S. V. et al. (2018) Importância das orientações em saúde para familiares de crianças com doença falciforme. Rev Bras Enferm, 71 (6), $3150-8$.

Gomes, I. L. V. et al. (2019). Doença falciforme: saberes e práticas do cuidado integral na Rede de Atenção a Saúde. EdUECE.

Kikuchi, B. A. (2007). Assistência de enfermagem na doença falciforme nos serviços de atenção básica. Rev. bras. hematol. hemoter, 29 (3), $331-338$.

Lapão, L. V., et al. (2017). Atenção primária à saúde na coordenação das redes de atenção à saúde no Rio de Janeiro, Brasil, e na região de Lisboa, Portugal. Ciênc. saúde colet., 22 (3), 713-724.

IPECE. (2012). Informe 23: Perfil da raça da população cearense. Fortaleza, 2012. https://www.ipece.ce.gov.br/wp-content/uploads/sites/45/2012/12/Ipece_ Informe_23_fevereiro_2012.pdf

Manga, H. B.; DeBaun M. R. \& Kassim, A. A. (2016). Epidemiology and treatment of relative anemia in children with sickle cell disease in sub-Saharan Africa. Expert Rev Hematol, 9 (11), 1031-1042.

Monteiro, A. S. S. et al. (2017). Estratégias para a popularização dos conhecimentos sobre a doença falciforme. Rev. Baian. Saúd. Públic, 41 (4), $1013-1024$.

Moraes, L. X. et al. (2017). Doença falciforme: perspectivas sobre assistência prestada na atenção primária. J. res.: fundam. care. online, 9 (3), 768 -775. 
Research, Society and Development, v. 10, n. 5, e45410515078, 2021

(CC BY 4.0) | ISSN 2525-3409 | DOI: http://dx.doi.org/10.33448/rsd-v10i5.15078

Oliveira, P. P. et al. (2018). Avaliação de famílias de crianças com doença falciforme. Investigación en Enfermería: Imagen y Desarrollo, 20 (2), 1-11.

OPAS/OMS BRASIL -Organização Pan Americana - OPAS/ Organização Mundial da Saúde - OMS (2017). Falciforme. http://www.paho.org/bra/ind ex.php?op tion=com_content $\&$ view=article $\&$ id $=395:$ doenca-falciforme $\&$ Itemid=539

Pereira, S. A. S. et al. (2018). Aplicativos móveis para o manejo da doença falciforme: revisão integrativa. Acta Paul Enferm, 31 (2), 224-32.

Rosenfeld, L. G. et al. (2019). Prevalência de hemoglobinopatias na população adulta brasileira: Pesquisa Nacional de Saúde 2014-2015. Rev. Bras. Epidemiol., $22(2), 1-9$

Sarat, C. N. F. et al. (2019). Prevalência da doença falciforme em adultos com diagnóstico tardio. Acta Paul Enferm, 32 (2), 202-209.

Silva, H. D. et al. (2013). Anemia falciforme e seus aspectos psicossociais: O olhar do doente e do cuidador familiar. Rev. Cuidarte, 4 (1), 475-483. 